\section{O REBORDO OCIDENTAL DA MESETA E A DEPRESSÃO TECTÓNICA DA LONGROIVA}

1. Entre a Cordilheira Central e o rio Douro estende-se um vasto e monótono planalto atravessado por um alinhamento de relevos residuais que formam a serra da Marofa. De notável platitude próximo da fronteira espanhola, esta topografia, que constitui um elemento da superfície da Meseta, perde a sua rigidez para ocidente do rio Côa. Ainda assim, a norte da serra da Marofa, vemo-la nitidamente atravessar este rio e prolongar-se até às vizinhanças do Douro peio magnífico nível de Vila Nova de Foz Côa. Mas imediatamente a oeste deste nível a superfície da Meseta termina-se brus. camente de encontro a um degrau de direcção geral NNE-SSO, que segue o Rio do Vale da Vila, a vertente ocidental da depressão da Longroiva c se continua para sul, passando por Marialva e Rabaçal.

Vários indícios revelam a natureza tectónica deste degrau Talhado ora nos xistos ora nos granitos, o seu traçado geral é bastante rectilíneo; observado de certa distância dá impressão de vigorosa escarpa e no pormenor nada faz lembrar um regolfo de embutimento entre duas superfícies de erosão. Além disso ele fica no enfiamento de um importante desligamento fini-hercínico que atravessa Trás-os-Montes oriental (1) e, prolongando-se para sul, parece penetrar no seio da Cordilheira Central até Unhais da Serra (2). Esta velha cicatriz tectónica foi sensível à orogenia alpina: em Trás-

( ${ }^{2}$ Ver Antonio Ribeiro et alia, «Estado actual dos conhecimentos sobre a geologia de Trás-os-Montes oriental», Boletim da Sociedade Geológica de Portugal, Lisboa, 1965, vol. xvi, pp. 93-110.

$\left.{ }^{2}\right)$ Ver Suzanne Daveau, «Structure et relief de la Serra da Estrela», Finisterra, Lisboa, 1969, vol. IV, pp. 31-63 e 159-197.
-os-Montes ela é seguida por um alinhamento de depressões, na Cordilheira Central produziram-se movimentos recentes segundo esta mesma directriz (S. Daveau, ob. cit., p. 176) e foi muito provàvelmente ao longo dela que se deu no Nordeste da Beira o balançamento da superfície da Meseta desde o sopé da Cordilheira Central, onde apresenta altitudes à volta de $800 \mathrm{~m}$, até ao nível de V. N. de Foz Côa, onde desce a $400 \mathrm{~m}$ de altitude.

Imediatamente a sul do Douro este acidente é sublinhado por um belo vale de fractura, o vale da Vila (est. I, A), que separa duas superfícies planas, talhadas numa mesma rocha (") e desniveladas de cerca de $300 \mathrm{~m}$. O vale da Vila é, assim, um vale de linha de falha. A existência de um degrau anterior à instalação do Rio do Vale da Vila evidenciam-se na dissimetria das vertentes: a vertente oriental, bastante jovem, encontra equivalente na parte baixa da vertente ocidental, constituindo ambas um vale em $\mathrm{V}$, cuja frescura mostra a rápida erosão vertical em função do Douro e a partir do nível de V. N. de Foz Côa; a parte superior da vertente ocidental, que se escalona de $400 \mathrm{~m}$ (nível de V. N. de Foz Côa) a cerca de $700 \mathrm{~m}$ (superfície plana superior) está, pelo contrário, bastante degradada pela dissecção densa e confusa típica dos xistos.

$\overline{\mathbf{E}}$ um degrau esbatido deste tipo que se vê no sector de Muxagata, onde o acidente tectónico, muito nítido em observação de fotografia aérea, não foi explorado pela dissecação (fig. 1). A vertente ocidental da depressão da Longroiva apresenta o mesmo aspecto: uma topografia ondulada descendo até ao cimo de uma escarpa que domina o fundo da bacia. Não é assim a área granítica a sul da Longroiva onde a superfície da Meseta atravessa o alinhamento tectónico, embora com uma topografia menos lisa, indo terminar-se a curta distância contra um degrau mais ou menos contínuo mas sempre nítido. Tudo se passa como se a escarpa de falha inicial tivesse recuado paralelamente a ela própria nos granitos, enquanto que nos xistos se teria processado um rebaixamento em função de uma escorrência solicitada pelo com-

(3) Xistos ardosíferos muito duros que explicam em parte a conservaçăo do nivel de V. N. de Foz Côa. Estes xistos comportam-se como rocha resistente em relação aos granitos de Freixo de Numão. 


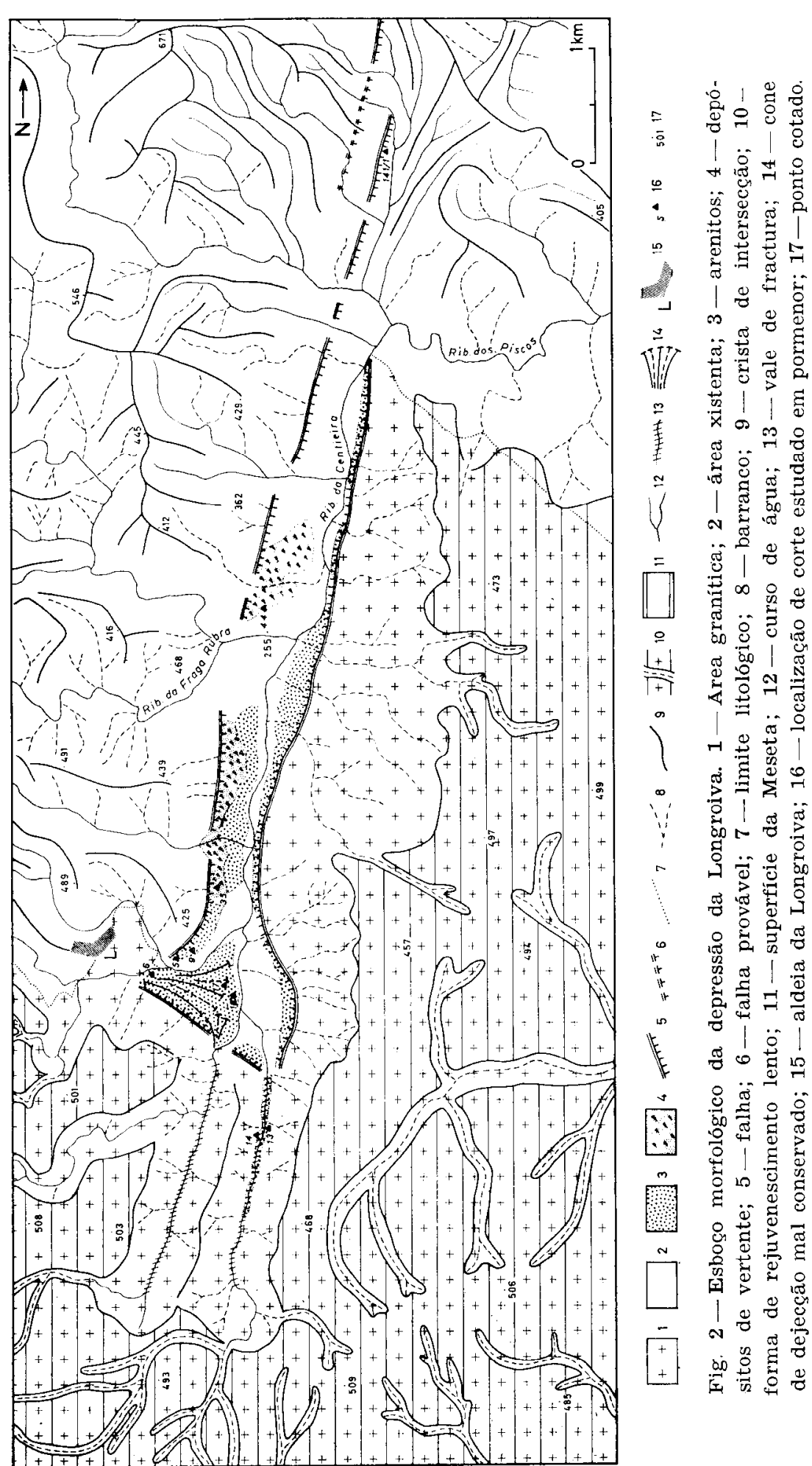

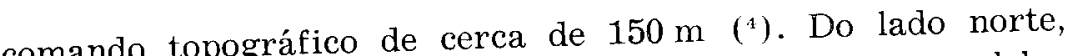
onde uma série de pequenos vales grosseiramente paralelos vêm dar ao fundo da bacia, os limites não são muito nítidos. Pelo contrário, do lado sul, a depressão termina bruscamente encontro a uma vigorosa escarpa granítica cortada por dois vales de fractura paralelos e de direcção NNE-SSO, vale dos Moinhos e o vale Talhado, que deixam entre eles uma distância semelhante à largura média da depressão (fig. 2) Assim é-se tentado a pensar que estas duas fracturas postas em evidência pela erosão vertical constituem o prolongamento de duas falhas paralelas, responsáveis pelas escarpas longitudinais; como estas fracturas não se encontram no prolongamento das escarpas, aparecendo pelo contrário nìtidamente deslocadas para leste, este dispositivo sugere a existência de uma falha transversal que explicaria a abrupta terminação meridional da bacia (").

3. Contornando o fundo da depressão e assentando directamente no substrato encontra-se um arenito argiloso de cor esbranquiçada ou cinzento-esverdeada, pouco consolidado e sem estratificação aparente, que ocupa a maior extensão de um alargamento em triângulo, dominado pela povoação da Longroiva, e aparece em retalhos descontínuos junto das duas escarpas longitudinais (fig. 2). Já fora dos limites da depressão este arenito insinua-se pelo vale Talhado e observa-se, do lado norte, num talude da E. N. 102, a cerca de $2 \mathrm{~km}$ a sul do desvio para Muxagata, sublinhando o rebordo ocidental da Meseta. Raramente se vê o contacto entre este depósito e as escarpas, sobretudo do lado oriental. Mas em vários pontos se verifica que o arenito não sofre nenhuma modificação de fácies junto da escarpa xistenta: isto significa claramente que o arenito é anterior à formação do degrau e que ambos se encontram por contacto anormal. Efectivamente, no caminho que da povoação da Longroiva conduz à

(4) A depressão da Longroiva situa-se num contacto entre xistos e oranitos que mede a rejeição horizontal média do desligamento fini-hercinico.

() Esta ideia deve-se a ANTónio RIBEIro, que conhecia já os prolemas morfológicos fundamentais da depressão da Longroiva antes de eu me interessar pelo mesmo assunto. 
veiga observa-se, a $250 \mathrm{~m}$ antes do entroncamento com a E. N. 102 (corte 5), uma bela falha em que o xisto cavalga ligeiramente o arenito (est. II, B). A mesma falha inversa se pode observar, embora com menor nitidez, no limite norte da bacia, próximo da Quinta do Marvão.

Temos assim a prova geológica da natureza tectónica da vertente ocidental da depressão da Longroiva. Tudo leva a crer que a escarpa oriental tenha tido a mesma origem, mas aqui nenhum corte permite ver claramente o tipo de contacto com o depósito. A penetração do arenito ao longo do vale Talhado não deixa de ser um facto estranho: a explicação mais simples talvez seja a formação de uma fractura aberta, numa fase de descompressão tectónica, logo preenchida pelo depósito que cobria o planalto. $\hat{\mathrm{E}}$ provável que o mesmo tenha sucedido no vale dos Moinhos, onde a ribeira terá sido responsável pelo desaparecimento do depósito, processo que se verifica hoje no vale Talhado.

Sobre o arenito argiloso observa-se em vários cortes um arenito mais grosseiro, onde se distinguem perfeitamente, a olho nu, além dos grãos de quartzo, grãos de feldspato e palhetas de mica branca. Esta formação arcósica inclui veios de calhaus de quartzo filoniano, angulosos ou levemente boleados, que podem atingir $10 \mathrm{~cm}$ de eixo maior. No corte 17 existem, entre os elementos maiores deste depósito, calhaus de granito mais ou menos rolados, de dimensões semelhantes aos de quartzo, e no corte $141 / 1$, num arenito arcósico do mesmo tipo, intercalam-se pequenos fragmentos de xisto. Aliás, nas vizinhanças da vertente xistenta, o arenito arcósico apresenta por via de regra cor avermelhada e parece ter recebido contribuição dos xistos.

A existência de calhaus de quartzo e de granito e de fragmentos de xisto, que não existem no arenito argiloso, assim como a abundância de grãos de feldspato, mostram que o arenito arcósico se formou, pelo menos em parte, a favor de uma erosão mecânica das rochas que constituem o substrato. O enriquecimento em calhaus de quartzo poderá ser o resultado da desagregação e alteração dos elementos de xisto e de granito durante o transporte ou mesmo no decurso da sedimentação. A estratificação entrecruzada, que se verifica em certos casos (nomeadamente nos cortes 16 e 17), parece mostrar que o transporte se fez em regime torrencial; nestas condições, o fraco ou nulo rolamento dos calhaus de quartzo significa que o transporte foi bastante curto. Parece razoável admitir-se que este depósito seja consequência de uma deformação tectónica responsável, senão por um primeiro esboço do graben da Longroiva, ao menos por um rejogo do acidente fini-hercínico.

Dois pequenos retalhos de depósito, situados já na superfície da Meseta mas a curta distância do actual rebordo granítico que a limita pelo ocidente, poderão servir de apoio a esta última ideia. Num deles (corte 151/1, est. III, A), em A dos Barreiros, a cerca de $7 \mathrm{~km}$ a leste do rebordo da Meseta, observa-se uma sobreposição de arenito argiloso e de arenito arcósico, este último com grãos de feldspato visíveis a olho nu e veios entrecruzados de calhaus de quartzo sub-rolados que ultrapassam frequentemente $10 \mathrm{~cm}$ de eixo

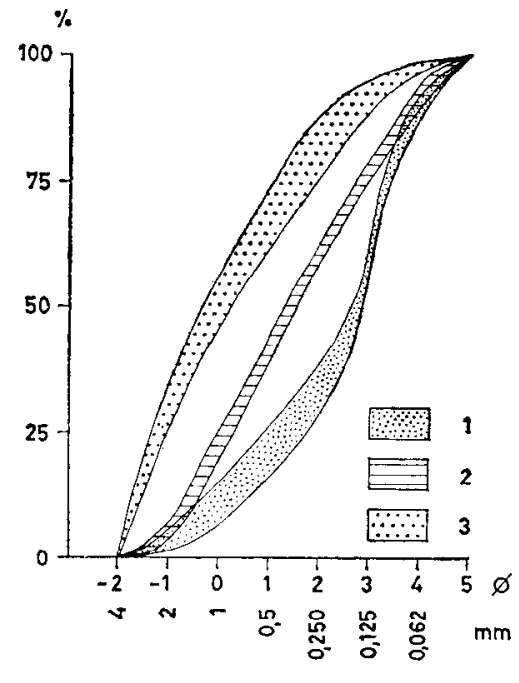

Fig. 3-Distribuição das curvas granulométricas acumulativas dos arenitos de Longroiva. 1 - Arenito argiloso fino (amostras $9 / 1 ; 16 / 2$; $17 / 3)$; 2 - arenito argiloso grosseiro (amostras $6 / 1 ; 9 / 3 ; 9 / 4$; tras $13 / 3 ; 16 / 1 ; 17 / 1)$. $13 / 2)$; 3 - arenito arcósico (amosmaior; entre os calhaus distinguem-se alguns elementos de rochas cristalinas. Encostado ao filão de quartzo do v. g. de Santa Bárbara (536), a SE de Coriscada, conservou-se um outro minúsculo retalho de depósito, desta vez apenas a $3 \mathrm{~km}$ do degrau ocidental da Meseta. Trata-se de um arenito arcósico, acinzentado e relativamente fino na base, de cor avermelhada e mais grosseiro na parte superior do corte, onde se observam leitos de calhaus de quartzo boleados e pequenos elementos de rochas cristalinas. Adiante veremos em que medida uma mudança climática poderá intervir na explicação destes depósitos. Mas qualquer que seja a causa imediata da sua formação, climática 
ou tectónica, eles são certamente correlativos de um relevo diferenciado.

4. As percentagens relativas da fracção arenosa e da fracção argilo-limonosa, assim como as medianas e as curvas granulométricas (quadro I e fig. 3), não só confirmam a distinção, feita no terreno, entre arenito arcósico e arenito argiloso, mas permitem distinguir neste último uma fácies fina e outra mais grosseira. Quando várias amostras foram

QUADRO I

Composição fundamental e granulometria dos depósitos da Longroiva

Fraç̧ão Fraç̧āo argilo- $\begin{gathered}\text { Ciranulometria } \\ \text {-limonosa }\end{gathered}$ da fraçãa arenosa Amostra arenosa limonosa da rraç̧ão areno

$\begin{array}{lrrrrl} & & (\%) & (\%) & \text { Md \% } & \text { Qd ? } \\ \text { Arenitos } & 9 / 1 & 69,8 & 24,7 & 2,85 & 0,8 \\ \text { argilosos } & 16 / 2 & 45,0 & 48,1 & 2,65 & 1,225 \\ \text { finos } & 17 / 3 & 68,3 & 28,8 & 2,75 & 1,05 \\ & 6 / 1 & 83,2 & 16,3 & 1,25 & 1,425 \\ \text { Arenitos } & 9 / 3 & 82,1 & 17,9 & 1,45 & 1,4 \\ \text { argilosos } & 9 / 4 & 82,4 & 16,7 & 1,5 & 1,375 \\ \text { grosseiros } & 13 / 2 & 82,3 & 16,7 & 1,2 & 1,225 \\ & 13 / 3 & 87,4 & 12,5 & 0,2 & 1,975 \\ \text { Arenitos } & 16 / 1 & 89,7 & 10,0 & 0,35 & 1,25 \\ \text { arcósicos } & 17 / 1 & 92,4 & 5,6 & 0,1 & 1,325\end{array}$

colhidas num mesmo corte, como foi o caso do corte 9, verifica-se que a fácies fina aparece sob a fácies grosseira. Os arenitos da depressão da Longroiva parecem formar, assim, uma sequência detrítica de tendência negativa (carácter cada vez mais grosseiro do depósito) que pode significar tanto uma degradação do clima como uma deformação tectónica ou os dois fenómenos ao mesmo tempo.

No arenito argiloso a fracção argilosa é constituída por montmorilonite, caulinite e ilite, com nítido predomínio da montmorilonite; no arenito arcósico encontra-se uma associação de montmorilonite, caulinite e ilite, sem predomínio evidente de nenhum destes minerais. Esta mesma associação se verifica no arenito fino da base do corte de $\mathrm{A}$ dos Barreiros. Mas tanto no arenito arcósico, que culmina este último corte, como no de Santa Bárbara, a argila dominante é a caulinite, associada a vestígios de ilite ou de montmorilonite. $\mathrm{O}$ arenito arcósico da Longroiva assim como o arenito da base do corte de A dos Barreiros parecem, pois, fazer a transição entre dois tipos de depósito, um fino em que a argila dominante é a montmorilonite e outro grosseiro em que a caulinite é o mineral argiloso quase exclusivo. $\mathrm{O}$ depósito montmorilonítico, mais antigo do que o depósito caulinítico, terá encontrado condições favoráveis à sua conservação na área deprimida da depressão da Longroiva.

$O$ arenito argiloso fino do graben da Longroiva, sem feldspato conservado e com uma percentagem relativamente elevada de argilas em que domina a montmorilonite, pode considerar-se como uma formação correlativa de uma arenização intensa, em clima de tendência quente e húmida e provàvelmente em condições de deficiente drenagem. Se o arenito argiloso grosseiro tem valor estratigráfico, ele mostrará uma tendência para a erosão mecânica, como o prova a fraca percentagem da fracção argilosa e o aparecimento de grãos de feldspato nas fracções mais grosseiras (servem de exemplo as amostras 9-3 e 9-4). A erosão mecânica das rochas do substrato evidencia-se nitidamente, como foi dito, no arenito arcósico da Longroiva; a modificação mineralógica da fracção argilosa, que é neste caso muito escassa, consiste numa melhor representação da caulinite e talvez da ilite de origem detrítica. Como a caulinite, tal como a montmorilonite, exige para a sua formação temperatura e humidade relativamente elevadas, o arenito arcósico deve antes indicar uma deformação tectónica do que uma degradação do clima.

A presença quase exclusiva de caulinite na fracção argilosa do depósito grosseiro de $\mathrm{A}$ dos Barreiros $\mathrm{c}$ no de Santa Bárbara, ambos correlativos de uma importante erosão mecânica, parece um fenómeno aberrante, contraditório. A explicação mais simples da participação, nestes depósitos, de produtos de erosão mecânica e de intensa alteração química, seria o aparecimento de um relevo vigoroso, de origem tectónica, num ambiente climático do tipo quente e húmido. Mas é provável que uma fase de alteração química e talvez de estabilidade tectónica tenha precedido a formação dos referidos depósitos, alteração que explicaria a generalidade 
da natureza essencialmente caulinítica da fracção argilosa dos depósitos da Meseta (servem de exemplos, além dos citados, as arcoses de Nave de Haver e os derrames de material grosseiro alimentados pela serra da Marofa).

Em suma, verifica-se aqui a mesma sucessão de depósitos com montmorilonite e de depósitos com caulinite observada por Galopim dE CARvalHo em vários outros pontos do país. Assim, os arenitos argilosos da Longroiva e os arenitos arcósicos de A dos Barreiros e de Santa Bárbara podem ser equivalentes laterais, respectivamente, do complexo montmorilonítico e do complexo ilito-caulinítico definidos por aquele autor $\left({ }^{\circ}\right)$. As idades oligo-miocénica e pliocénica que lhes são atribuídas serão aqui admitidas como hipótese de trabalho, na falta de elementos de datagem mais precisos, e com toda a prudência que merecem as correlações estratigráficas baseadas em semelhanças de fácies. Se aproximarmos o que aqui se passa com o que se verifica na serra da Estrela (S. DAveau, ob. cit.), estes depósitos serão indício de duas fases de movimentos tectónicos, separados por um período de estabilidade e de alteração do tipo tropical húmido: uma posterior aos depósitos com montmorilonite, que terá originado o graben da Longroiva, permitindo aqui a conservação destes materiais; outra correlativa da formação dos depósitos com caulinite, durante a qual terão provàvelmente rejogado tanto o graben como o rebordo ocidental da Meseta.

5. Sempre que se verifica sobreposição dos arenitos da Longroiva, o arenito arcósico cobre o arenito argiloso. Mas por vezes eles aparecem lado a lado, o que parece ser devido ao abarrancamento do arenito argiloso pelo arenito arcósico. Em todo o caso, a espessura muito variável atingida pelo arenito argiloso parece mostrar uma érosão prévia deste antes da deposição do arenito arcósico. Hoje a bacia está em vias de exumação e os arenitos desapareceram já ao longo da ribeira da Centieira. Assim é difícil saber-se qual terá sido a espessura original destes depósitos.

$\left({ }^{3}\right)$ A. M. Galopim DE Carvalho, Contribuição para o conhecimento geológico da bacia terciária do Tejo, Serviços Geológicos de Portugal Memória n. 15 (Nova Série), Lisboa, 1969.
Foi no alargamento em triângulo, dominado pela povoação da Longroiva, que os arenitos se conservaram melhor. No corte 9 eles afloram desde o fundo da depressão, que se encontra aqui a $280 \mathrm{~m}$, até à altitude de $320 \mathrm{~m}$. O limite entre estes depósitos e a escarpa granítica transversal situa-se entre $330 \mathrm{~m}$ e $340 \mathrm{~m}$ de altitude. A escarpa granítica fronteira a este alargamento apresenta-se muito vigorosa e abrupta até esta mesma altitude, sendo daqui até ao planalto nìtidamente degradada, aspecto que parece verificar-se também junto de Quintãs e da Quinta dos Areais. Poderemos ver nestes indícios a altitude aproximada a partir da qual começou a exumação da bacia? A única coisa que se pode dizer com relativa segurança é que o desnivelamento tectónico que deu origem à depressão, medido entre a base dos depósitos da Longroiva e a altitude do planalto, foi da ordem dos $200 \mathrm{~m}$.

No referido alargamento em triângulo, que é limitado pelas ribeiras da Concelha e da Centieira, encontra-se em vários cortes um depósito grosseiro que assenta directamente sobre os arenitos, contrastando fortemente com estes pela constituição e pelas dimensões dos elementos. Este material grosseiro compõe-se de blocos e calhaus de granito, com dimensões que variam entre 2 e $50 \mathrm{~cm}$ de eixo maior, e de calhaus de quartzo menos abundantes e geralmente pequenos (2 a $4 \mathrm{~cm}$ ), uns e outros envolvidos, sem estratificação aparente, numa areia granítica, por via de regra escassa. Os mais pequenos calhaus de granito estão rolados, enquanto que os calhaus de quartzo e os blocos de granito são angulosos ou apresentam apenas as arestas boleadas. Enquanto que à saída do vale dos Moinhos os cortes mostram apenas os elementos citados de granito e de quartzo (est. III, B), à saída do vale da ribeira da Concelha aparecem, além destes, elementos de xisto. Há, assim, uma nítida concordância entre a constituição petrográfica deste depósito e a constituição das vertentes dos vales referidos. $O$ transporte, suficiente para rolar os calhaus de granito, mas apenas afeiçoando as arestas dos calhaus de quartzo, pode cifrar-se em escassos quilómetros, tal como a extensão dos ditos vales. Os grandes blocos, angulosos ou com arestas boleadas, devem corresponder a material fornecido pelas vertentes a uma distância muito curta do local da sedimentação. Os vários retalhos deste depósito permitem 
reconstituir um antigo cone de dejecção à saída do vale da Concelha e outro mais pequeno à saída do vale dos Moinhos. Actualmente a ribeira da Concelha e a ribeira da Centieira aparecem embutidas de 4 a $5 \mathrm{~m}$ em relação à base destes cones. Um depósito semelhante se observa no vale Talhado (cortes 13 e 14), mas aqui os elementos são menos grosseiros e por vezes a matriz é relativamente abundante, onde se vêem claramente sinais de escorrência. Este terraço domina de cerca de $4 \mathrm{~m}$ o talvegue da actual ribeira, a qual apresenta regime torrencial, arrastando por vezes enormes blocos e destruindo muros de protecção à sua passagem. Esta ribeira morde um baixo terraço de composição semelhante aos elementos transportados actualmente.

Do lado da escarpa xistenta derramou-se sobre os arenitos um depósito de vertente, constituído por via de regra de calhaus de xisto e de quartzo filoniano angulosos, envolvidos numa matriz argilo-limonosa mais ou menos abundante. Este depósito apresenta fácies muito variadas. No corte 35 ele forma uma verdadeira brecha em que os elementos de xisto e de quartzo, com dimensões que variam entre alguns milímetros e $2 \mathrm{dm}$ de comprimento, se distribuem de maneira caótica numa matriz relativamente abundante. No corte 44, mais complexo, observa-se a seguinte sobreposição, de baixo para cima (fig. 4): arenito duro de cimento calcário (44-2); depósito argilo-limonoso de cor vermelho vivo (44-3), com grãos de quartzo e pequenos fragmentos líticos (observados à lupa binocular) e incluindo concreções calcárias (44-4); finalmente, duas assentadas de brecha constituída por pequenos elementos de xisto boleados e de quartzo filoniano angulosos, com cimento muito escasso (44-10). Brechas semelhantes se observam com frequência na base da vertente xistenta, mas aqui os próprios elementos de xisto são completamente angulosos. A massa argilo-limonosa também se observa em vários outros cortes; como ela não contém calhaus de quartzo, não é de admitir uma alteração local de material xistento grosseiro.

Distinguem-se, assim, neste depósito xistento, fases e condições diversas de deposição e de fornecimento dos materiais. A presença de concreções calcárias, certamente posteriores à formação do depósito argilo-limonoso, devem ser
- resultado de evoluções pedológicas em períodos de clima relativamente quente e seco, com fases húmidas. Pelo contrário, o depósito do corte 35 apresenta o aspecto de uma corrente de solifluxão consolidada, correlativa, provàvelmente, de um período frio do Quaternário. As brechas de cimento escasso e de elementos pequenos parecem também traduzir um clima mais frio que o actual, sendo a crioclastia responsável pelo fornecimento de abundante calhausada. Uma gelifraccão intensa, num período de frio mais persistente e su:icientemente húmido, seguida de gelifluxão, poderá explicar o depósito argilo-limonoso, sem que se possa apresentar aqui

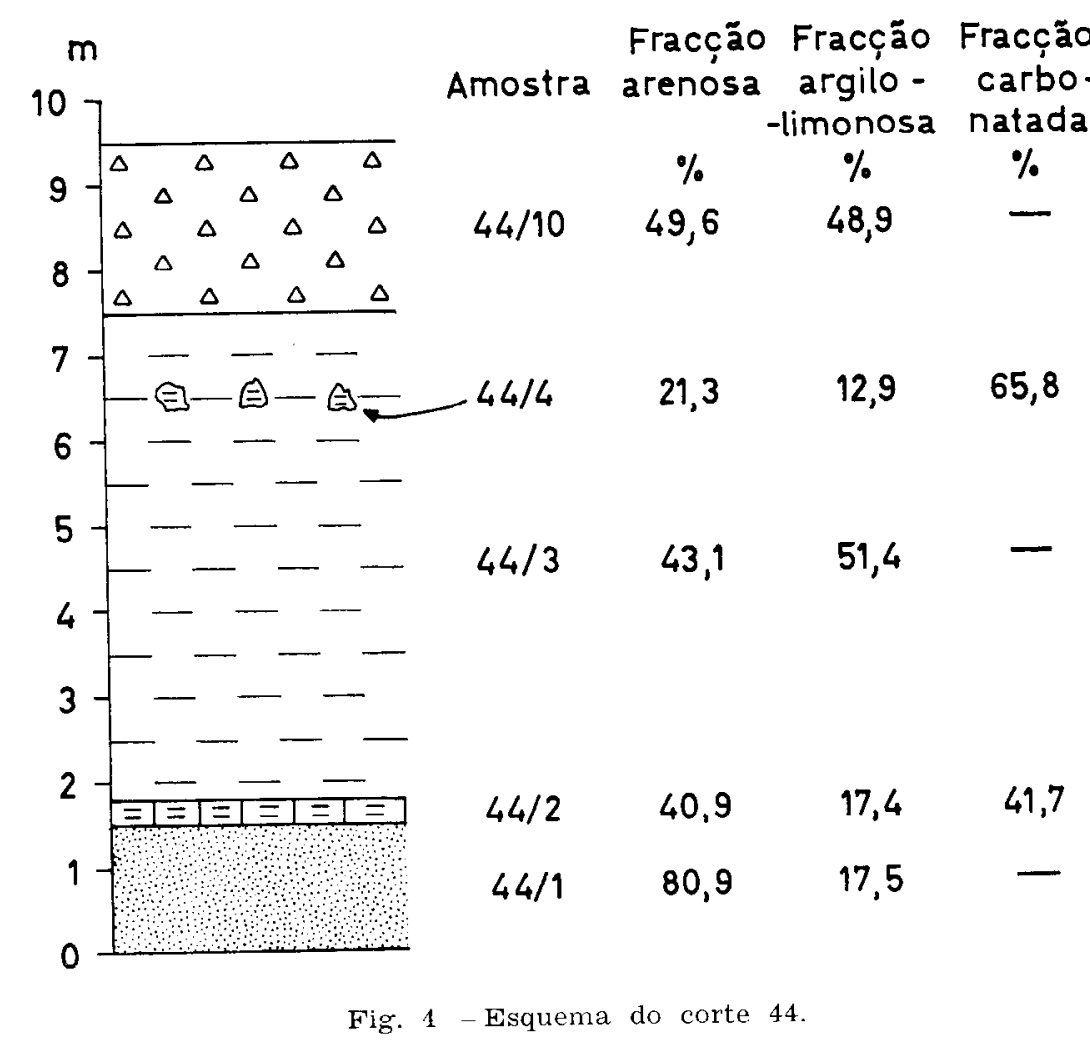

argumento decisivo. Segundo esta hipótese, a massa argiio-limonosa seria provàvelmente correlativa do Riss, as crostas calcárias, do Riss-Würm, e as brechas, do Würm. Em qualquer dos casos, estes depósitos parecem corresponder a derra- 
mes, na base das vertentes, sem ligação com um escoamento concentrado, por uma razão topográfica (vertentes abruptas) ou climática (favorecendo um regime de acumulação pelo fornecimento de abundantes detritos).

Estes depósitos graníticos e xistentos, nitidamente relacionados com as vertentes actuais, são as primeiras formações seguramente correlativas do graben da Longroiva como depressão topográfica. As escarpas actuais, que medem cerca de $150 \mathrm{~m}$, serão o resultado sobretudo de uma exumação ou de um novo rejogo tectónico posterior aos arenitos e anterior aos depósitos graníticos e xistentos? Por enquanto é bastante difícil responder a esta pergunta. Diremos simplesmente que, na primeira hipótese, não se compreende bem, como veremos a seguir, qual terá sido o organismo responsável pela exumação de uma tal massa de materiais. A segunda hipótese daria conta da relativa isoaltitude dos arenitos onde eles melhor se conservaram e também da dissimetria bem marcada da escarpa granítica: apenas a parte inferior, mais abrupta, seria o resultado de uma exumação recente. Aliás, no alinhamento de depressões que acompanham o desligamento fini-hercínico de Trás-os-Montes oriental e de que a Longroiva faz parte, conhecem-se importantes manifestações de movimentos tectónicos quaternários $\left({ }^{\top}\right)$.

6. Actualmente a erosão vertical constitui o processo mais activo da evolução morfológica. Observa-se, no entanto, uma dissimetria nítida de um e de outro lado da depressão da Longroiva: do lado ocidental os xistos apresentam uma rede densa de vales estreitos e profundos; do lado oriental, na área granítica, a incisão ganha importância apenas no rebordo da escarpa, onde o declive se torna forte. Esta dissimetria está evidentemente relacionada com a natureza litológica, sendo os xistos, pela sua impermeabilidade, particularmente favoráveis ao escoamento superficial. Além disso a vertente oci-

(') Por exemplo, na bacia de Macedo de Cavaleiros, a escarpa da serra de Bornes corresponde a uma falha posterior às rañas, depósitos considerados do Vilafranquiano (informação de A. RIBEIRo. Ver também P. Birot, «Les surfaces d'érosion du Portugal central et septentrional», Rapport Comm. Cartogr. Surf. Apl., U. G. I., Congrès Int. Géog., Lisbonne, 1949, pp. 75-77). dental xistenta, coincidindo com o bloco levantado da Meseta, encontra-se a uma altitude mais elevada do que a vertente oriental, e é possível, como se disse, que um balançamento do bloco ocidental tenha facilitado a drenagem no sentido da depressão.

Os dois organismos mais potentes da dissecção da vertente xistenta são a ribeira da Fraga Rubra e a ribeira do Vale das Portas, que se reúnem junto da Quinta da Veiga, antes de confluírem na ribeira da Centieira. Neste sector a escarpa xistenta encontra-se nitidamente recuada e em frente dela não se conservou nenhum retalho de depósito. Estas duas ribeiras apresentam regime torrencial, arrastando por vezes enormes quantidades de material grosseiro e danificando as vinhas da Quinta da Veiga. Os blocos de quartzo filoniano, boleados e por vezes de grandes dimensões, que se encontram nesta área, devem ser produto destas enxurradas. Algumas ribeiras mais pequenas, como a do Vale da Cerdeira, construíram um terraço à entrada da depressão, por diminuição de potência.

No planalto granítico assiste-se a uma desagregação granular cujos produtos são parcialmente transportados por uma fraca escorrência imperfeitamente organizada. $\mathrm{Na}$ vertente oriental do graben da Longroiva, esta desagregação, penetrando preferencialmente ao longo das diaclases e pequenas fracturas, deverá contribuir fortemente para a queda dos blocos, por vezes enormes ( 1 a $2 \mathrm{~m}^{3}$ ), que aí se observam. A queda de blocos, associada a uma dissecção deficiente, explica o maior vigor da escarpa granítica em relação à escarpa xistenta.

A ribeira da Centieira, que corre ao longo da depressão da Longroiva reunindo a drenagem da vertente ocidental, constitui o principal agente da exumação da bacia. Dèbilmente alimentada, com um declive muito fraco e encontrando no seu caminho materiais a transportar, não lhe resta energia para se encaixar no fundo da depressão e por isso divaga ao rés do substrato. Por vezes viu-se obrigada a abandonar aqui parte da carga que trazia, constituindo assim ela própria um obstáculo à incisão.

Esta ribeira sai da bacia da Longroiva por um cotovelo brusco e atravessa a escarpa oriental um pouco a norte do contacto xisto-granítico (fig. 2), correndo num vale jovem 
- vale da Ribeira dos Piscos - até à confluência com o rio Côa. Seria imprudente falar-se de epigenia ou de antecedência na explicação deste dispositivo: a ribeira da Centieira é um curso de água insignificante que se adaptou aos vários acidentes estruturais: servem de exemplo as fracturas do Vale dos Moinhos e do Vale Talhado, assim como o contacto xisto-granítico seguido pela Ribeira da Concelha, sua afluente. De resto, nem antecedência nem epigenia explicariam a mudança brusca de direcção à saída da bacia, a qual deve mais uma vez relacionar-se com uma adaptação estrutural, sugerida pelo traçado geométrico da maior parte do curso da Ribeira dos Piscos. A importância do vale drenado por esta ribeira deverá assim explicar-se por uma erosão vertical facilitada por fracturas e pela proximidade de um rio importante, o rio Côa. Não afastamos a hipótese, aliás muito provável mas difícil de confirmar, de que o traçado da Ribeira dos Piscos seja a herança de uma drenagem que se fez directamente do rebordo ocidental para a superfície da Meseta.

7. Do que ficou dito, uma ideia principal interessa reter: a natureza tectónica do contacto entre a superfície bem conservada da Meseta e os planaltos mais elevados que lhe ficam a ocidente. Estes planaltos constituem, pois, o prolongamento ocidental da superfície da Meseta. Mas se aqui a platitude continua a ser um aspecto fundamental da paisagem, um relevo mais movimentado, com formas por vezes pouco nitidas, substitui o traçado simples e rígido do planalto oriental. Não é difícil apontar-se como factores desta maior diversidade morfológica uma fracturação intensa, que se manifesta à primeira vista no traçado dos cursos de água, uma grande variedade petrográfica escondida sob, a designação vaga de granitos, um clima mais húmido que favoreceu a erosão diferencial, enfim, uma evolução morfológica perturbada pelas oscilações do nivel do oceano próximo. A dificuldade consistirá em definir o papel de cada um destes factores e estabelecer as etapas da evolução morfológica nesta área desprovida de depósitos superficiais.

\section{RÉSUMÉ}

Le rebord occidental de la Meseta et le bassin tectonique de Longroiva. La surface bien conservée de la Meseta qui s'étend de la Serra da Estrela au Douro constitue un important point de départ pour l'étude des hauts plateaux dénudés du Nord de la Beira. On fait ici l'analyse du contact entre ces deux grandes unités du relief du Nord du Portugal, dans le secteur du petit bassin tectonique de Longroiva. Ce rebord occidental de la Meseta a l'allure d'un escarpement de direction générale NNE-SSW, qui semble avoir une origine tectonique: taillé à la fois dans les schistes et les granites, son tracé est dans l'ensemble assez rectiligne et, observé de loin, il fait figure de relief vigoureux; en outre, il est situé sur le prolongement d'un vieux décrochement qui a dû rejouer à plusieurs reprises si l'on pense au nombre d'accidents tectoniques que l'on trouve suivant sa direction (alignement de fossés au nord du Douro; basculement de la Meseta au sud du Douro; fragmentation en horst et graben alternés dans la Serra da Estrela). Néanmoins, l'observation de détail fait perdre la notion de rigidité, de vigueur et de l'unité même de cet escarpement. Cela s'explique par l'érosion (atténuation de la pente dans les schistes; recul dans les granites) et par la complexité même de l'accident tectonique. Deux exemples: le plus grand rentrant du rebord occidental de la Meseta dans le secteur ici étudié (le rentrant de Marialva) est constitué par un ensemble de petits blocs basculés en touches de piano; la remontée du petit bassin de Moitas vers la haute surface de Trancoso et Moreira de Rei se fait en marches d'escalier.

Le bassin de Longroiva, étudié ici en détail, est un petit graben limité à l'est et au sud par des escarpements granitiques, vigoureux dans l'ensemble, et à l'ouest par un escarpement schisteux, assez dégradé, qui fait partie du rebord occidental de la Meseta. Son intérêt morphologique vient du fait qu'il a conservé des dépôts superficiels, devenus très rares dans les plateaux du Nord de la Beira. Ces dépôts constituent une séquence détritique de tendance négative: les grès argileux fins qui couvrent le fond du bassin deviennent de plus en plus grossiers vers le haut et aboutissent à un grès arkosique où l'on distingue à l'œil nu, outre les grains de quartz, des grains de feldspath, des paillettes de mica blanc et des lits de cailloux, parfois de granite et de schiste, mais surtout de quartz filonien, anguleux ou légèrement émoussés, qui peuvent atteindre $10 \mathrm{~cm}$ de longueur. On ne voit que très rarement le contact entre ces dépôts et les escarpements, mais on peut facilement vérifier que les grès argileux de la base de la séquence ne subissent aucune modification de faciès près de l'abrupt schisteux: cela montre clairement que les grès argileux et les schistes se trouvent en contact anormal. D'ailleurs, sur la route qui mène du village de Longroiva au bassin, on observe une belle faille inverse, les schistes chevauchant légèrement les grès argileux. Le caractère de plus en plus grossier des dépôts de Longroiva peut avoir ainsi une signification tectonique. 
La fraction fine des grès argileux est essentiellement constituée de montmorillonite, accompagnée de kaolinite et d'illite. Dans les grès arkosiques, on trouve une association de montmorillonite, kaolinite et illite sans prédominance d'aucun de ces minéraux. Sur la surface de la Meseta, à quelques kilomètres de son rebord occidental, on trouve, la Mesta, a quelques kim lambeaux de grès près de $\mathrm{A}$ dos Barreiros et de Santa Bárara, deux lamite, arkosiques grossiers où l'argile dominante est la kaolinite, associée à des vestiges d'illite et de montmorillonite. Les grès arkosiques du bassin de Longroiva semblent ainsi faire la transition entre un dépôt fin où de Longépót grossier où la l'argile dominante est la montmorillonite et un dépó gês à montmokaolinite est le minéral argileux presque exclusif. Le dépôt à montmorillonite, plus ancien que le dépôt à kaolinite, aurait trouvé des conditions favorables à sa conservation dans la dépression de Longroiva. Avec toute la prudence qu'exigent les corrélations stratigraphiques de datation, on fondées sur les faciès et faute d'éléments plus précis de datation, on pourrait rapprocher les grès argileux de Longroiva et les grès arkosique de A dos Barreiros et Santa Bárbara, respectivement, du complexe à de A dos Barexe à illite et kaolinit et kaolinite d'âge pliocène dont la succession a été maintes fois observee par GALOPIM DE CARVALHo dans les sédiments continentaux portugais. Comm dans la Serra da Estrela (d'après une étude récente de $\mathbf{S}$. Daveau) ces dépôts seraient l'indice de deux phases de mouvements tectoniques séparées par une période de stabilité relative et d'altération de type tropical humide qui expliquerait la nature essentiellement kaolinique de la fraction argileuse des dépôts grossiers de la Meseta: l'une, postérieure aux dépôts à montmorillonite, serait à l'origine du graben de Longroiva; l'autre serait corrélative de la formation des dépôts à kaolinite, durant laquelle auraient rejoué le graben et le rebord occidental de la Meseta.

Le bassin est en voie d'exhumation et les grès ont même tout à ait disparu le long de son cours d'eau principal. Ainsi est-il difficile d'évaluer leur épaisseur originelle. Sur ces grès, se sont épanchés des dépôts grossiers granitiques et schisteux en rapport net avec les versants actuels. Ces dépôts sont les premières formations sûrement corrélatives du graben de Longroiva en tant que dépression topographique. Il est difficile de savoir si les escarpements actuels, qui mesurent près de $\mathbf{1 5 0} \mathrm{m}$, sont surtout le résultat de l'exhumation ou d'un nouveau rejeu tectonique postérieur aux grès mais antérieur ou même corréatif des dépôts grossiers granitiques et schisteux. En tout cas, dans la première hypothèse on ne voit pas quel serait l'organisme responsable de l'enlèvement d'une telle masse de matériaux. La deuxième hypothèse rendrait mieux compte de l'isoaltitude relative des grès là où ils sont rendrait mieux compte de l'isoaltitude relative des grès là oú ils sont oriental: seule la partie inférieure, plus abrupte, serait le résultat d'une exhumation récente.

La nature même des dépôts de Longroiva ne permet pas de retracer de façon précise l'évolution du graben et du rebord occidental de la Meseta. Tout compte fait, l'idée générale à retenir est la nature tec- tonique, prouvée ici géologiquement, du contact entre la surface bien conservée de la Meseta et les plateaux plus élevés du Nord de la Beira.

\section{SUMMARY}

The western edge of the MLeseta and the tectonic basin of Longroiva. The well preserved surface of the Meseta which extends from th The Douro, constitues an important stanting point for the study of the bare high plateaux of the north of Beira. Here one analyses the contact between these two great relief elements of northern Portugal, in the area of the small tectonic basin of Longroiva. This Western edge of the Meseta has the appearance of an escarpment whose general direction in NNE-SSW, and which seems to be of tectonic origine: cut, at one and the same time, in the schists and granites, it outline is, on the whole, fairly rectilinear, and, considered from a distance, has the configuration of vigourous relief; moreover, it is situated on the Whe fault which must have recurred on several occasions if one thinks of the number of tectonic disturbances one finds along its course (alignement of troughs to the north of the Douro; th tiling of the Meseta to the south of the Douro, fragmentation, in alternating horst and graben in the Serra da Estrela). Nevertheless, study alternating horst and graben in the Serra da Estrela). Nevertheless, study of detail causes us to lose the notion of rigidity, vigour and the very unity of the escarpment. This is explained by erosion (flattening of the schists; recession of the granites) and by the very complexity of the tectonic disturbance. Two examples: the largest reentrant on the western edge of the Meseta in the sector studied here (the recess of Marialva) consists of a collection of small tilted blocks; the rise of the small basin of Moitas towards the high surface of Trancoso and Moreira de Rei comprises a flight of steps.

The basin of Longroiva, studied here in detail, is a small graben limited to the east and south by granite escarpments, on the whole, vigorous, and, to the west, by a schistous escarpment, fairly degraded, which is part of the western edge of the Meseta. Its morphological interest arises from the fact that it has preserved superficial deposits, which have become extremely rare in the plateaux of the north of Beira. These deposits represent a detrital sequence of a negative tendency. The fine clayey sandstones which cover the bottom of the basin become more and more coarse towards the top, ending up as an arkosic one may distinguish, with the naked eye, besides grains of quartz, feldspaths, flakes of white mica and beds of pebbles, sometimes of granite and schist but especially of filonian quartz, angular or slightly smoothed, which may reach a length of $10 \mathrm{~cm}$ Only very rarely does one see a contact between these deposits and the escarpments but one may easily see that the clayey sandstones of the base of the sequence undergo no modification of facies near the schistous wall; this clearly shows that the claycy sandstones and schists lie in abnormal contact. Besides, along the road which goes from the village of Longroiva to the basin, one may see a fine reversed 
fault, the schists slightly overlap the clayey sandstones. The more and deposits of Longroiva may thus have tectonic value.

The fine portion of the clayey sandstone consists essentially of montmorillonite, together with kaolinite and illite. In the arkosite sandstones one finds a grouping of montmorillonite, kaolinite and illite with no predominance of any one of these minerals. On the surface of the Meseta, a few kilometres from its western edge, near A. de Barreiros and Santa Bárbara one finds two shreds of coarse arkosite sandstones in which the dominant clay is kaolinite, associated with vestiges of illite and montmorillonite. The arkosite sandstones of the basin of Longroiva thus seem to constitute the transition between a fine deposit where the predominant clay is montmorillonite and a coarse deposit where kaolinite is virtually the only clayey mineral. The montmorillonite deposit, older than the kaolinite deposit, may have encountered conditions favourable to its preservation in the depression of Longroiva With all the care required of stratigraphic correlation based on the facies and absence of more precise dating evidence, one might group the clayey sandstones of Longroiva and the arkosed sandstones of A dos Barreiros and Santa Bárbara respectively, together with the montmorillonite complex of the Oligo-Miocene age and the illite and kaolinite complex of the Pliocene age whose series has many times been observed by GALOPIM DE CARvalHo in continental Portuguese sediments. Judging by the way things happen in the Serra da Estrela (according to a recent study by $\mathbf{S}$. DAvEAU), these deposits appear to be the sign of two phases of tectonic movements separated by a period of relative stability and weathering of the tropical humid type which would explain the essentially kaoline nature of the clayey portion of the coarse deposits of the Meseta: one, later than the montmorillonite deposits, would be the origin of the graben of Longroiva: the other would be correlated with the formation of the kaolinite deposits, during which a movement of the graben and western edge of the Meseta would have occurred.

The basin is in a process of exhumation and the sandstones have even disappeared along its principal watercourse. Thus it is difficult to evaluate their original thickness. On top of these sandstones have outpoured coarse granite and schistous deposits which clearly originated from the present slopes. These deposits are the prime formations certainly correlated with the graben of Longroiva when considered as a topographical depression. It is difficult to say if the present escarpments which measure almost 150 metres, are, above all, the result of the exhumation or of a new tectonic recurrance, later than the sandstones but earlier or even correlated with the coarse granite and schistous deposits. In any case, as far as the first hypothesis is concerned, one cannot see what was responsible for the removal of such a volume of material. The second hypothesis would account more favourably for the relative isoaltitude of the sandstones there where they are better preserved as well as for the clearly defined

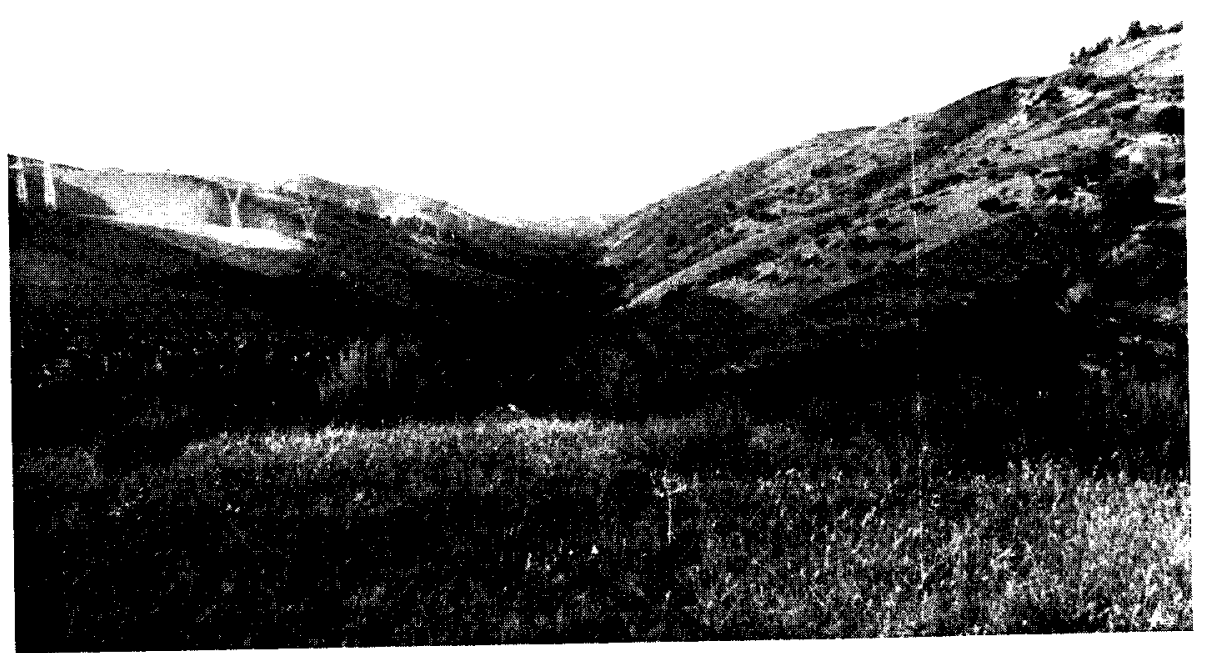

EsT. I, A - O vale da Vila.

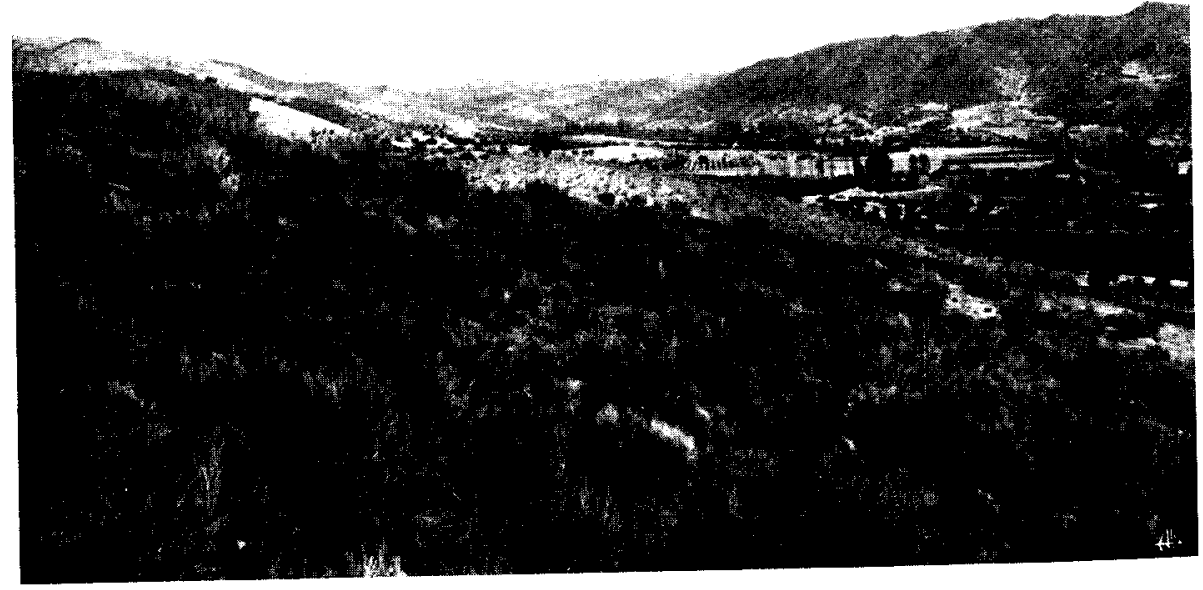

EST. I, B - Aspecto geral da depressão da Longroiva. 


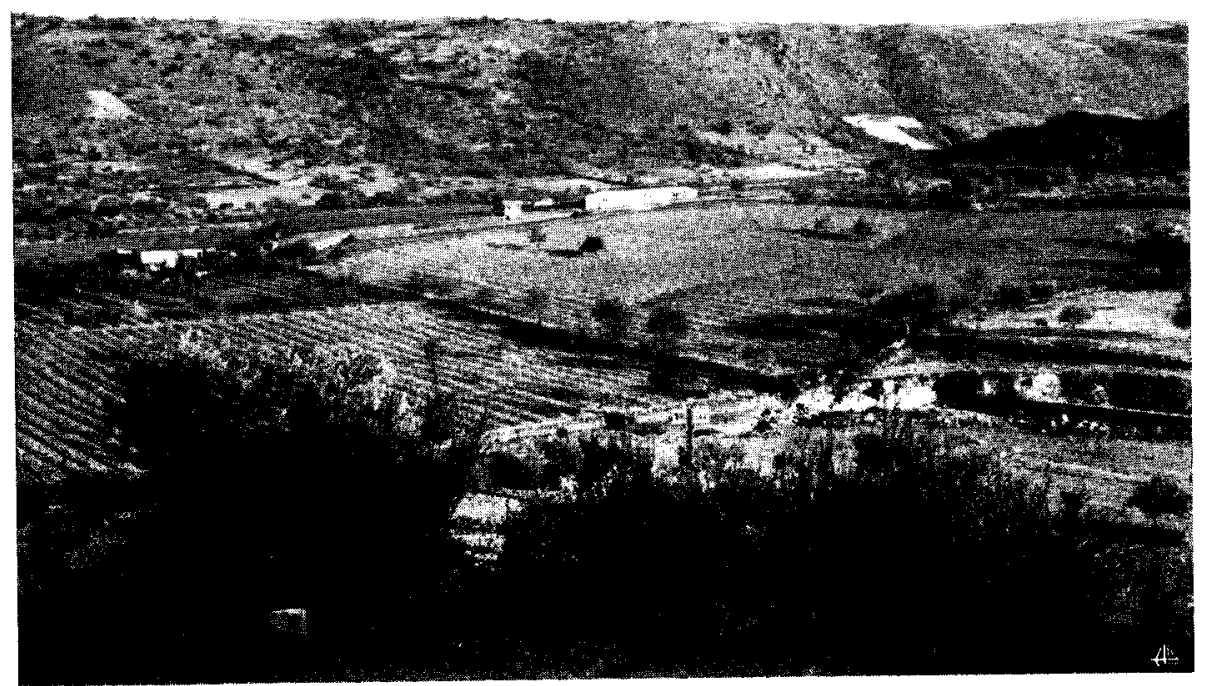

EsT. II, A - Esscarpa granítica oriental da Longroiva.

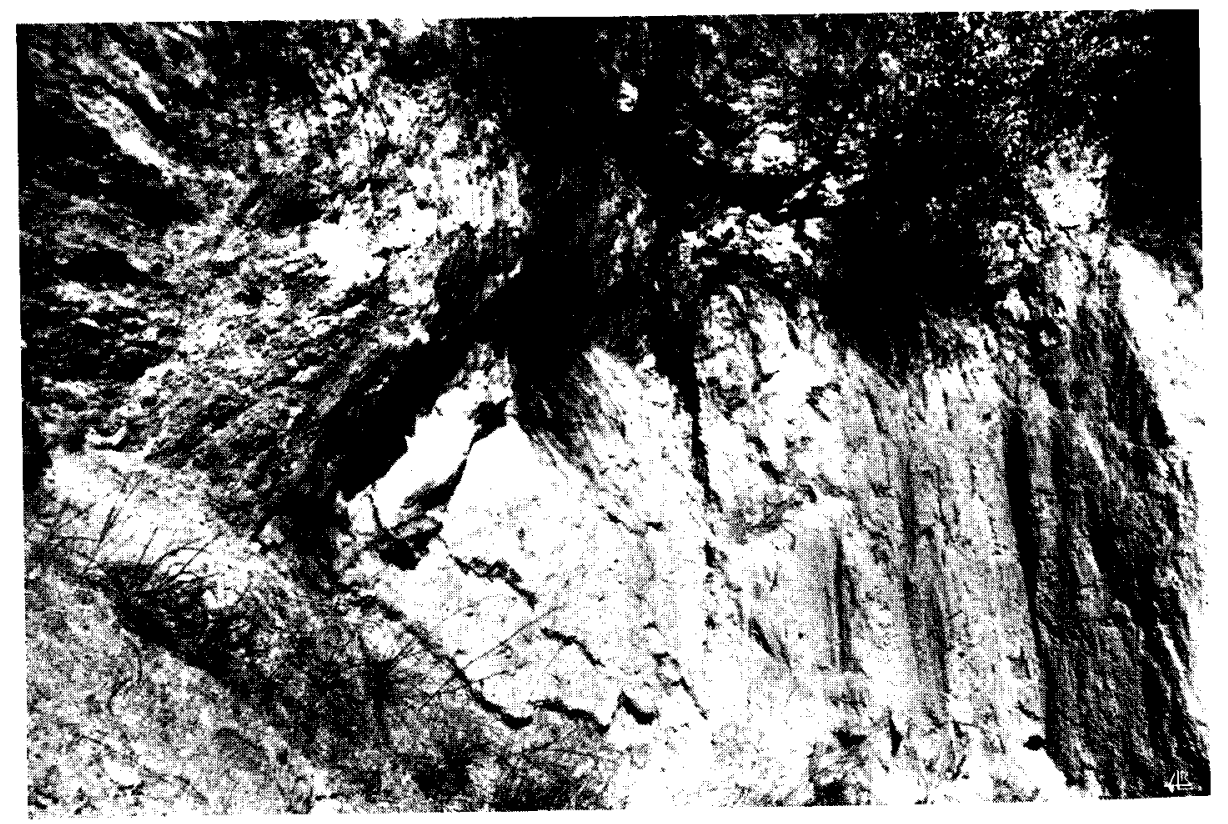

EST. II, B - Falha inversa da escarpa ocidental da Longroiva (os xistos cavalgam ligeiramente os arenitos). 


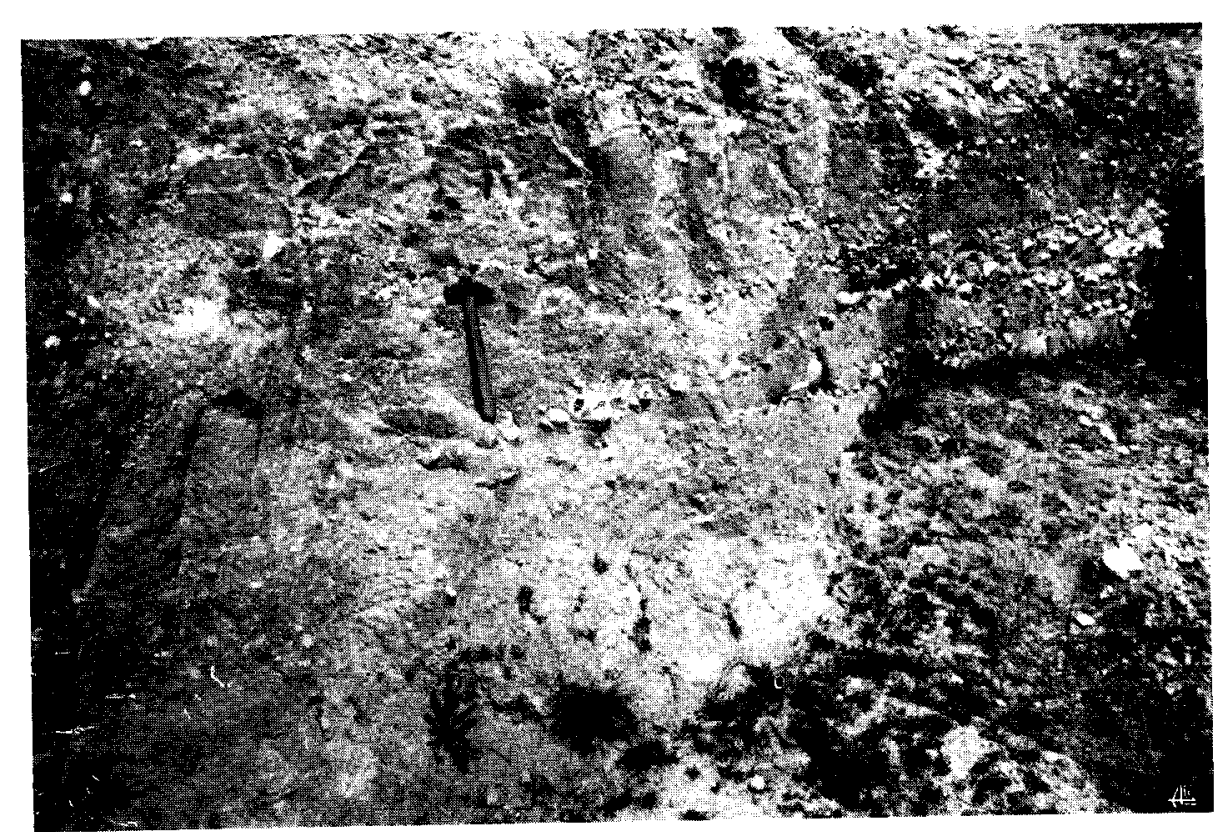

EST. III, A - Corte no arenito arcósico de A dos Barreiros (151-1).

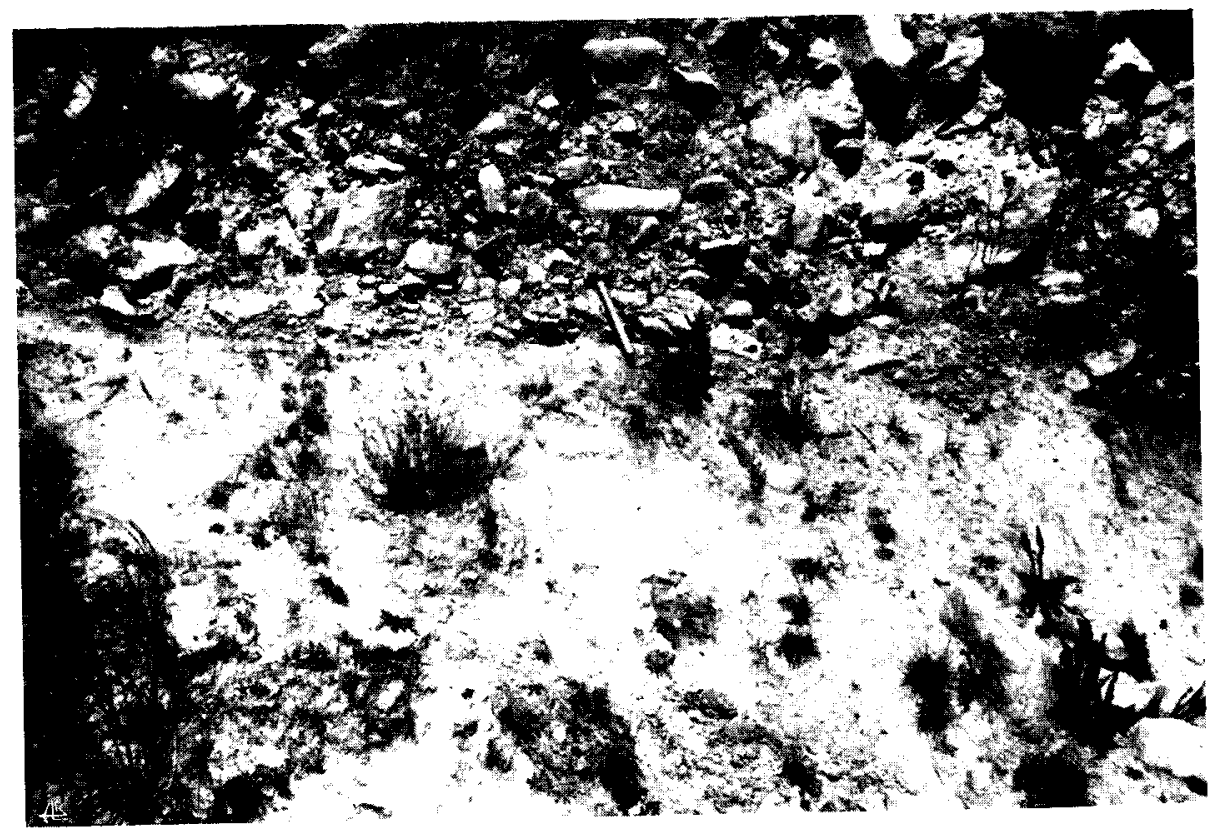

EST. III, B-Depósito granítico revestindo os arenitos da Longroiva. 
disparity of the eastern granite escarpment: only the lower part, more abrupt, would be the result of a recent exhumation.

The very nature of the deposits of Longroiva precludes any chance of understanding, in a more precise way, the evolution of the graben and the western edge of the Meseta. All things considered, the general idea one should retain is the tectonic nature, here proved geologically, of the contact between the well preserved surface of the Meseta and the more elevated plateaux of the north of Beira. 